\begin{tabular}{ccc}
\hline International Journal of Advanced Chemistry, 8(2)(2020) $198-202$ & \\
International Journal of Advanced Chemistry & Website: $w w w . s c i e n c e p u b c o . c o m / i n d e x . p h p / I J A C$ \\
RPC & Research paper \\
\hline
\end{tabular}

\title{
Development and validation of HPTLC method for the estimation of cefadroxil in bulk and tablet dosage form
}

\author{
Kirankumar S. V. ${ }^{1}$ *, Jose Gnana Babu C. ${ }^{1}$, Sowmya H G. ${ }^{1}$ \\ ${ }^{1}$ Department of Pharmaceutical Analysis, Bharathi College of pharmacy, Bharathinagara, K.M Doddi, Maddur Taluk, Mandya Dis- \\ trict, Karnataka, India - 571422 \\ *Corresponding author E-mail: kirankumarsv95@gmail.com
}

\begin{abstract}
A novel and simple HPTLC method has been developed for the estimation of Cefadroxil (CFD) in bulk and pharmaceutical dosage form on silica gel precoated aluminum $60 \mathrm{~F} 254$ plates, $(10 \mathrm{~cm} \times 10 \mathrm{~cm})$ with $0.25 \mathrm{~mm}$ thickness. The separation was carried out using ethyl acetate: chloroform $(8: 2 \mathrm{v} / \mathrm{v})$ as mobile phase. The Chromatographic scanning was carried out at $254 \mathrm{~nm}$. The $\mathrm{Rf}( \pm \mathrm{SD})$ values were found to be $0.38 \pm 0.05$ for CFD. The linearity for analyte was in the range 100-500 ng/band for CFD with correlation coefficients, $\mathrm{r} 2=0.9996$. The percentage recovery obtained for CFD was in the range of $99.28-100.13 \%$ respectively. The proposed method was optimized and validated as per the ICH guidelines 17.
\end{abstract}

Keywords: Cefadroxil; HPTLC; Method Validation; Tablet Dosage Form.

\section{Introduction}

Cefadroxil is a semi-synthetic first generation oral cephalosporin drug effective against gram-positive and gram-negative bacterial infections and similar to cephalexin and cephradine in structure and spectrum of antibacterial activity ${ }^{1}$. It is used in the treatment of mild to moderate infections of the respiratory and urinary tracts, skin and soft tissue infections. It has been used in the prophylaxis of recurrent urinary tract infections in children. The chemical name of Cefadroxil is (6R, 7R)-7-[(2R)-2-(4-hydrophenyl) acetamido]-3-methyl-8-OXO5-thia-1- azabicycio [4.2.0] oct-2-ene-2-carboxylic acid hydrate. It has a molecular formula of $\mathrm{C}_{16} \mathrm{H}_{17} \mathrm{~N}_{3} \mathrm{O}_{5} \mathrm{~S}$ and molecular weight of $363.38 \mathrm{~g} / \mathrm{mol}$. Cefadroxil is freely soluble in water and methanol ${ }^{2}$.<smiles>CC1=C(C(=O)O)N2C(=O)[C@@H](NC(=O)[C@@H](N)c3ccc(O)cc3)[C@H]2SC1</smiles>

Fig. 1: Chemical Structure of Cefadroxil.

Literature survey reveals that there were some analytical methods have been reported for the estimation of Cefadroxil in pure drug and pharmaceutical dosage forms by using UV $\mathrm{UV}^{3-8}$ spectrophotometric, HPLC ${ }^{9-14}$ and HPTLC ${ }^{15-16}$ so far.

The aim of present work is to develop and validate a novel, simple, accurate and specific HPTLC method for estimation of Cefadroxil in bulk and tablet dosage form.

\section{Materials and methods}

\subsection{Chemicals and reagents}


- Cefadroxil pure form was obtained as a gifted sample from Microlabs pharma industry located at Bommasandra, jigani link road, Bangalore and its pharmaceutical dosage form Cefadrox 10 Tablets labelled claim 500mg. Manufactured by Aristo pharmaceuticals Pvt ltd, Baddi at Mumbai. Batch no: B712K117 procure from local pharmacy Mandya.

- Ethyl acetate and chloroform are of analytical grade were available in the laboratory of Bharathi College of pharmacy, bharathinagara.

- $\quad$ Silica gel $60 \mathrm{~F}_{254} 20 \times 10 \mathrm{~cm}$, precoated plates, layer thickness $0.25 \mathrm{~mm}$ sup- plied by Anchrom Technologists, Mumbai (Merck, Darmstadt, Germany).

\subsection{Instrumentation and chromatographic conditions}

The standard solution ranging from 100-500ng/band for CFD was applied as bands using a Camag $100 \mu$ l sample syringe (Hamilton, Bonaduz, Switzerland) with an automatic TLC Sampler Linomat V (Camag, Muttenz, Switzerland). (Number of tracks 5, track distance from the left plate edges $15 \mathrm{~mm}$, distance from plate bottom $10 \mathrm{~mm}$, band length $6 \mathrm{~mm}$, distance between bands $4.5 \mathrm{~mm}$.).Before analysis the layers were pre- developed with methanol to clean them and activated at $110^{\circ} \mathrm{C}$ for $5 \mathrm{~min}$. Analysis was performed on silica gel precoated aluminum plate $60 \mathrm{~F}_{254}, 10 \times 10 \mathrm{~cm}, 0.25 \mathrm{~mm}$ layer thickness. The plates were developed in a twin trough glass chamber with saturation of 30 min with the mobile phase. The mobile phase consists of ethyl acetate: chloroform $(8: 2 \mathrm{v} / \mathrm{v})$. After development, plates were dried and were observed under Camag TLC Visualizer. Chromatographic scanning was per- formed using a Camag TLC scanner III in the reflectance absorbance mode at $254 \mathrm{~nm}$ for all measurements and operated by the WINCAT'S software version 2.0. The source of radiation utilized was a deuterium lamp emitting a continuous UV spectrum between 190 and $400 \mathrm{~nm}$. Concentrations of the compound chromatographed were determined from the intensity of the diffused light. Evaluation was by peak areas with linear regression.

2.3 Preparation of Standard Stock Solution and Working Standard Solution

The standard stock solution of CFD containing $1000 \mu \mathrm{g} / \mathrm{ml}$ was prepared by dissolving accurately weighed quantity of $50 \mathrm{mg}$ of Cefadroxil into a 50ml volumetric flask and dissolved in a minimum volume of methanol and diluted to the required volume with methanol. The working standard solution was prepared in the concentration range 100-500 ng/band for CFD by appropriate dilutions of the above standard stock solution with methanol.

\section{Results and discussion}

\subsection{Optimization of solvent system and chromatographic conditions}

Chromatographic separation was carried out on the stock solution of CFD. Initially the plates were spotted with $10 \mu 1$ of stock solution and developed by linear ascending development method using neat solvents like toluene, hexane, methanol, chloroform, dichloromethane, ethyl acetate, acetone, acetonitrile, etc. with or without chamber saturation. Based on the results of these initial chromatograms, binary and ternary mixtures of solvents were tried to achieve optimum peak parameter. The final mobile phase consisting of Ethyl acetate: chloroform $(8: 2 \mathrm{v} / \mathrm{v})$.was optimized since good $\mathrm{R}_{\mathrm{f}}$ value of 0.38 for CFD was obtained as shown in Fig. 1 . The samples were applied in form of bands on precoated aluminum sheets of silica gel $60 \mathrm{~F}_{254}$. Linear ascending development was carried out in a twin trough glass chamber $(20 \mathrm{~cm} \times 10$ $\mathrm{cm}, 10 \times 10 \mathrm{~cm}$ ), without saturation. The length of chromatogram run was $85 \mathrm{~mm}$. The developed plates were dried in the current of dry air. Chromatographic scanning was performed in the absorbance mode at $254 \mathrm{~nm}$

\subsection{Method validation}

As per the ICH guidelines ${ }^{17}$, the method validation parameters checked were linearity, accuracy and precision, limit of detection (LOD), limit of quantitation (LOQ), robustness and specificity.

\subsection{Calibration curve}

The linear regression data for the calibration curves showed a good linear relationship over the concentration range 100-500 ng/band. Linear regression equation was found to be $\mathrm{Y}=6.5528 \mathrm{X}+283.94$ and $\mathrm{R}^{2}=0.9996$. Data of linearity study are listed in Table 1 .

Table 1: Linearity Study of Cefadroxil

\begin{tabular}{llll} 
& & Table 1: Linearity Study of Cefadroxil \\
\hline SL No & Concentration ng/band & Peak Area & Statistical analysis \\
\hline 1 & 100 & 933.8 & \\
2 & 200 & 1590.5 & Slope $=6.5528$ \\
3 & 300 & 2280.7 & Intercept $=283.94$ \\
4 & 400 & 2876.9 & Correlation coefficient $=0.9996$ \\
5 & 500 & 3567 & \\
\hline
\end{tabular}

*Mean of six estimations. 


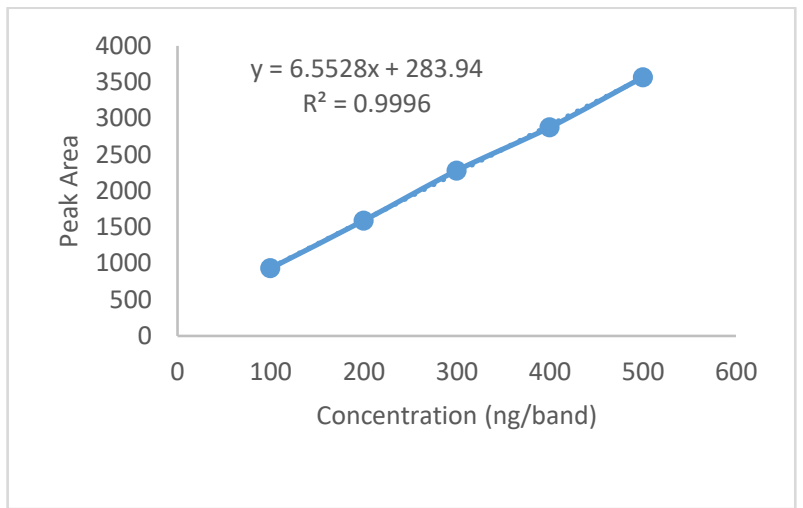

Fig. 2: Calibration Curve of Cefadroxil.

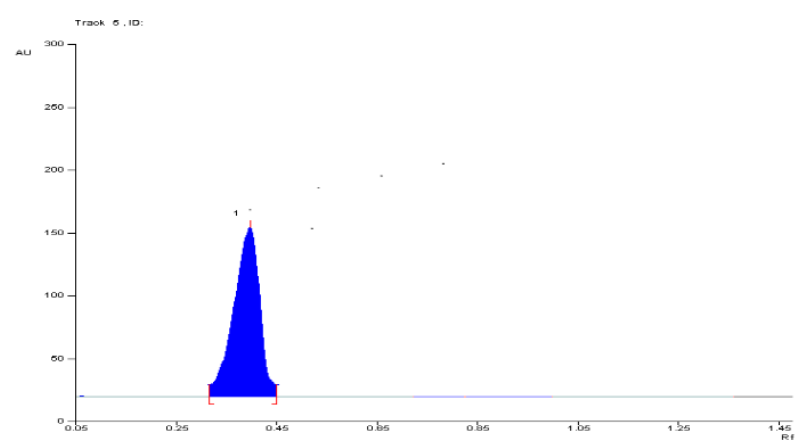

Fig. 3: HPTLC Chromatogram of Cefadroxil.

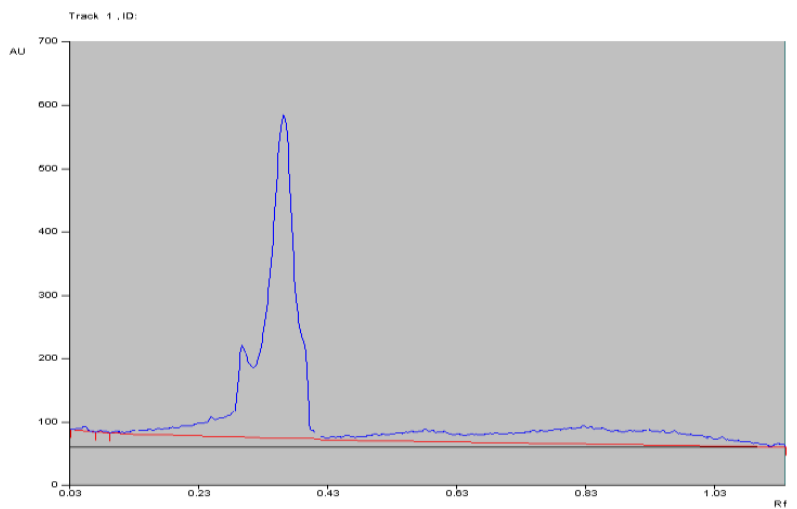

Fig. 4: Overlain Spectrum of Cefadroxil.

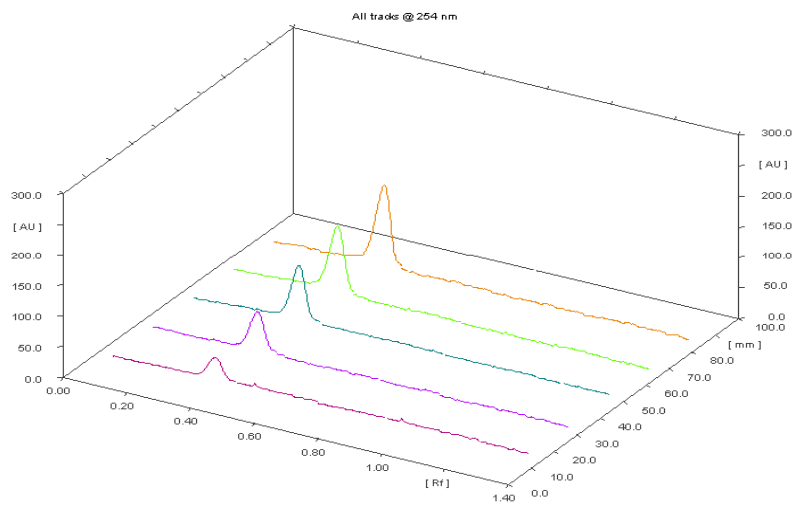

Fig. 5: 3D Spectra of All 5 Tracks.

\subsection{Precision}

The precision of the method is determined by intra-day and inter-day variation studies by using three concentrations over the range of the method. In the intra-day studies, the method was repeated 3 times a day for standard and sample solutions and \% RSD was calculated. For inter day variation studies, 3 repeated measurements of standard and sample solutions were made on 3 consecutive days and \% RSD was calculated. Results are listed in Table 2. 
Table 2: Precision Study of Cefadroxil

\begin{tabular}{|c|c|c|c|c|c|}
\hline SL No & Concentration ng/band & $\begin{array}{l}\text { INTRADAY } \\
\text { Mean of area }\end{array}$ & $\%$ RSD & $\begin{array}{l}\text { INTERDAY } \\
\text { Mean of area }\end{array}$ & $\%$ RSD \\
\hline 1 & 100 & 923.2 & 0.190 & 932.2 & 0.303 \\
\hline 2 & 200 & 1587.9 & 0.127 & 1579.8 & 0.204 \\
\hline 3 & 300 & 2275.7 & 0.086 & 2289.7 & 0.109 \\
\hline 4 & 400 & 2887.4 & 0.076 & 2879.1 & 0.068 \\
\hline 5 & 500 & 3575.2 & 0.080 & 3568.9 & 0.064 \\
\hline
\end{tabular}

*Mean of three estimations at each level.

\subsection{Method sensitivity (LOD and LOQ)}

LOD and LOQ were calculated using S.D (standard deviation of the response) and $b$ (slope of the calibration curve) using the relationship $\mathrm{LOD}=(3.3 \times \mathrm{s} . \mathrm{d}) / \mathrm{b}$ and LOQ $=(10 \mathrm{x}$ s.d $) / \mathrm{b}$. The LOD and LOQ were found to be 7.52 and $22.58 \mathrm{ng} / \mathrm{spot}$, respectively. This indicates the sensitivity of the method.

\subsection{Specificity}

The method is found to be specific since no interfering spots were seen in Chromatogram of placebo and tablet triturate and $R_{f}$ values of standard and sample were compared. Peak purity for both the analyte was assessed by comparing spectra at three different regions of the spot i.e. acquired at the peak start(S), peak apex $(\mathrm{M})$ and end of the peak(E) obtained from the band (Table 3$)$. As the correlation values are greater than 0.999 which indicates that the peaks are pure.

\subsection{Ruggedness}

When the method is performed under the variant conditions. This includes different analysts, laboratories, instruments, temperature etc. Ruggedness was determined between two different analysts. It was found to be rugged (Table 3 ).

Table 3: Summary of Validation Parameters of Cefadroxil

\begin{tabular}{ll}
\hline Parameters & Cefadroxil \\
\hline Detection Wavelength $(\mathrm{nm})$ & 254 \\
Beer s Law Limit $(\mathrm{ng} / \mathrm{band})$ & $100-500$ \\
Regression Equation $(\mathrm{y}=\mathrm{mx}+\mathrm{c})$ & $\mathrm{Y}=6.5528 \mathrm{x}+283.94$ \\
Slope $(\mathrm{m})$ & 6.5528 \\
Intercept $(\mathrm{c})$ & 283.94 \\
Correlation coefficient $\left(\mathrm{r}^{2}\right)$ & 0.9996 \\
Limit of detection $(\mathrm{ng} / \mathrm{spot})$ & 7.52 \\
Limit of quantitation $(\mathrm{ng} / \mathrm{spot})$ & 22.58 \\
Ruggedness & 0.154 \\
Robustness & Robust \\
Specificity & Specific \\
\hline
\end{tabular}

\subsection{Accuracy}

Accuracy of the analytical method is the closeness of test results obtained by the method to the true value. To assess the accuracy of the proposed method, recovery studies were carried out at 3 different levels i.e. 50\%, 100\% and 150\%. The formulation concentration was kept constant and varied pure drug concentration. Accuracy results were shown in table.4.

Table 4: Accuracy Study of Cefadroxil

\begin{tabular}{|c|c|c|c|c|}
\hline Drug/Label claim & Initial amount of drug (ng/band) & Amount of Standard drug (ng/band) & Drug Recovered & $\% \mathrm{RSD}$ \\
\hline \multirow{3}{*}{ Cefadroxil 500mg } & \multirow{3}{*}{300} & 150 & 100.13 & 0.733 \\
\hline & & 300 & 99.28 & 0.134 \\
\hline & & 450 & 99.81 & 0.077 \\
\hline
\end{tabular}

*Mean of three estimations at each level.

- Robustness

Robustness study is done by changing the volume $( \pm 2 \mathrm{ml})$ and composition $( \pm 5 \%)$ of mobile phase and chromatograms were run. Robustness of the method was studied at $300 \mathrm{ng} / \mathrm{band}$ of CFD, respectively. During robustness study $\mathrm{R}_{\mathrm{f}}$ values, standard deviation of the peak areas and $\%$ RSD was calculated for each parameter. $\%$ RSD values were found to be less than $2 \%$ which indicates robustness of the method (Table 5).

Table 5: Robustness of the Method of Cefadroxil

\begin{tabular}{ll}
\hline Parameters & $\%$ RSD \\
\hline Mobile phase volume $( \pm 2 \mathrm{ml})$ & 0.92 \\
Development distance $( \pm 5 \mathrm{~cm})$ & 0.75 \\
Duration of saturation $( \pm 2)$ & 0.78 \\
Time from spotting to chromatography $( \pm 10 \mathrm{~min})$ & 0.39 \\
Time from chromatography to scanning $( \pm 10 \mathrm{~min})$ & 0.81 \\
\hline
\end{tabular}

* Mean of three estimations at each level.

\section{- Analysis of Tablet Formulations}

Twenty tablets were weighed accurately and a quantity of tablet triturate equivalent to $50 \mathrm{mg}$ of CFD was weighed and dissolved in the 40 $\mathrm{ml}$ of methanol with the aid of ultra-sonication for $10 \mathrm{~min}$ and solution was filtered through Whatman filter paper No. $41 \mathrm{into}$ a $50 \mathrm{ml}$ volumetric flask. Filter paper was washed with the methanol, adding washings to the volumetric flask and volume was made up to mark. The solution was suitably diluted with methanol to get of $300 \mu \mathrm{g} / \mathrm{ml}$ of CFD was used for calibration curve. The amount of drug present per 
tablet was estimated from the respective calibration curves. The method was evaluated in terms of assay of commercially available tablets containing CFD. Three replicate determinations were performed on the accurately weighed amounts of tablet triturate. After carrying assay, percentage found was 99.39 for CFD. The \%RSD was found to be 0.95 for CFD

\section{Conclusion}

The present analytical method was validated as per the ICH guidelines and met the acceptance criteria. It was concluded that the developed analytical method was simple, accurate, specific, economical and sensitive and can be used for the routine analysis of Cefadroxil in bulk drug and its pharmaceutical dosage forms.

\section{Acknowledgement}

We like to thanks Management, Director, Principal, Teaching and non-teaching staff of Bharathi College of pharmacy and my dear friends for their continous co-operation and support.

\section{References}

[1] https://en.wikipedia.org/wiki/Cefadroxil

[2] https://www.drugbank.ca>drugs.

[3] Patel C, Patel K, Sen DJ, Badmanaban R, Parikh A. Development and validation of spectroscopic methods for the estimation of Cefadroxil in tablet dosage forms. J Chem Pharm Res. 2010; 2(2):163-67.

[4] Sethuraman S, Radhakrishnan K, Venkateswarlu V, Sravani M, Ramathulasi G, Bhanuteja S. Estimation and degradation monitoring of Cefadroxi in pharmaceutical dosage form by using UV-spectroscopy. Asian J Res Bio Pharm Sci. 2014; 2(1):27-33.

[5] Pradip D, Santosh J, Sumit G, Laxmi J. Development and validation of UV spectroscopic estimation of Cefadroxil in bulk and tablet dosage form using area under curve method. Indo American J Pharm sci. 2015; 2(2):581-6.

[6] Dey S, Kalyani K, Samyuktha B, sahoo SK, Mohapatra S, Murthy PN et al. Development and validation of a UV-vis spectrophotometric method for the estimation and degradation monitoring of Cefadroxil in bulk and pharmaceutical dosage forms. Int J Chem Res. 2010; 1(1):29-34.

[7] Shantier SW, Gadkariem EA, Ibrahim KE, EL-Obeid HA. Spectroscopic determination of Cefadroxil in bulk and dosage form using sodium hydroxide. J Chem. 2011; 8(3):1314-22. https://doi.org/10.1155/2011/568620.

[8] Kumar CA, Gurupadayya BM, Sloka SN, Chandan RS, Thejaswini JC. Colorimetric determination of Cefadroxil and ceftriazone in pharmaceutical dosage forms. Tropical J Pharm Res, 2011; 10(1):81-88. https://doi.org/10.4314/tjpr.v10i1.66546.

[9] Rao KG, Uma B, Shankar B, Naik BM. Development and validation of RP-HPLC method for the estimation of Cefadroxil Monohydrate in bulk and its tablet dosage form. J Adv Pharm Edu \& Res. 2014; 4(1):71-74.

[10] Anjum A, Shetty SK, Ahmed M, Sridhar BK, Vijaya KM. Development and validation of RP-HPLC method for the quantitative estimation of Cefadroxil monohydrate in bulk and pharmaceutical dosage forms. Int J Chem Sci. 2012; 10(1):150-58.

[11] Rahim N, Naqui SB, Shakeel S, Iffat W, Muhammad IN. determination of Cefadroxil in tablet/capsule formulations by a validated reverse phase high performance liquid chromatographic method. Pakistan J Pharm Sci. 2015; 28(4):1345-49.

[12] Shukla RS, Pandey S, Bangale R. Novel HPLC analysis of Cefadroxil in bulk formulation. Asian J Pharm. 2008; 2(2):106-109. https://doi.org/10.4103/0973-8398.42497.

[13] Vittaladevaram V, Pragada H. Development of method for analysis and quantification of Cefadroxil in different pharmaceutical formulations using HPLC. Int J Pharm Bio Sci. 2017; 7(1):27-31. https://doi.org/10.21276/ijpbs.2017.7.1.4.

[14] Margo BA, Salgado HR, Development and validation of an innovative method for the determination of Cefadroxil monohydrate in capsules. World J Pharm Sci. 2017; 6(8):2074-91. https://doi.org/10.20959/wjpps20178-9875.

[15] Pisal VB, Deshpande PB, Gandhi SV, Bhangale Y. High performance thin layer chromatographic determination of Potassium clavulanate and Cefadroxil in combined dosage form. Der Pharmacia Sinica. 2011; 2(2):79-85.

[16] Dhoka MV, Chopade SS. Method development \& comparative statistical evaluation of HPLC \& HPTLC method for simultaneous estimation of Cefadroxil monohydrate \& Ambroxol hydrochloride. Indo Global J Pharm Sci. 2012; 2(2):203-12.

[17] ICH, Q2 (R1) Validation of Analytical Procedures: text and methodology;2005. 